Jones, A. S., Rizvi, S. B. H. \& Stacey, M. (1958). J. gen. Microbiol. 18, 597-606

\title{
The Phosphorus-containing Compounds of Gram-positive and Gram-negative Organisms in Relation to the Gram Staining Reaction
}

\author{
By A. S. JONES, S. B. H. RIZVI ANd M. STACEY \\ Chemistry Department, The University, Edgbaston, Birmingham 15
}

\begin{abstract}
SUMMARY: The phosphorus-containing compounds of certain Gram-positive and Gram-negative organisms were estimated by a modification of the Schmidt \& Thannhauser (1945) procedure. Another method (Mitchell \& Moyle, 1950, 1951 $a, b$, 1954) in which pentosenucleic acid (PNA) was estimated from the optical absorption of the 'PNA fraction' at $260 \mathrm{~m} \mu$. was found to be inaccurate, because of the presence of ultraviolet-absorbing impurities. A more accurate method for estimating PNA has now been developed, in which the nucleotides are separated from impurities by paper electrophoresis. The results thus obtained show that non-nucleotide phosphorus-containing compounds are present in the 'PNA fraction' of both Grampositive and Gram-negative organisms. There is, therefore, no evidence to connect these compounds with the Gram staining properties of Gram-positive microorganisms (cf. Mitchell \& Moyle, 1950, 1951 $a, b, 1954$ ).
\end{abstract}

It has been shown that magnesium ribonucleate, in association with certain proteins and possibly polysaccharides, is the complex responsible for the retention of the Gram stain in Gram-positive micro-organisms (Henry \& Stacey, 1943, 1946; Henry, Stacey \& Teece, 1945; Jones, Muggleton \& Stacey, 1950). These conclusions, which have been largely confirmed by other workers (Bartholomew \& Umbreit, 1944) have since been questioned by Mitchell \& Moyle $(1950,1951 a, b, 1954)$ who claimed that Gram-positive organisms contain a particular phosphoric ester fraction (XSP) which is absent from Gramnegative species and that this 'XSP factor' is responsible for the retention of the stain in the Gram reaction. In view of these claims, it was decided to reinvestigate the problem and in particular to analyse various micro-organisms for their XSP content.

\section{METHODS}

Organsisms used and methods of cultivation. The following organisms were used: (a) Gram-positive; baker's yeast (Distillers Co.), Bacillus subtilis, Clostridium welchii, Sarcina lutea, Streptococcus faecalis (NCTC, 370); (b) Gram-negative; Aerobacter aerogenes (NCTC 8172), A. cloacae (NCTC 8813), Escherichia coli and Klebsiella pneumoniae (NCTC 3279). They were grown in a medium containing $(\%, w / v): 0 \cdot 5$, Lab Lemco; 1 , Oxoid bacteriological peptone; 1, glucose; 0.5 , sodium chloride. The solution of Lab Lemco, peptone and sodium chloride was adjusted to $\mathrm{pH} \mathrm{9,} \mathrm{boiled} \mathrm{for} \mathrm{5-10} \mathrm{min.} \mathrm{and}$ the resulting precipitate filtered off. The filtrate was adjusted to $\mathrm{pH} 7.5$ and the solution autoclaved at $10 \mathrm{lb} . / \mathrm{sq}$. in. for $15 \mathrm{~min}$. Sterile glucose solution was then added aseptically. The complete medium was inoculated with an 
$18 \mathrm{hr}$. culture of the required organism. The cultures of Aerobacter aerogenes, A. cloacae, Bacillus subtilis and Sarcina lutea were aerated during growth. After incubation at $37^{\circ}$ for $18 \mathrm{hr}$. (except for $S$. lutea which was grown for $48 \mathrm{hr}$.) the organisms were centrifuged down, washed with $0.85 \%(\mathrm{w} / \mathrm{v})$ sodium chloride and freeze-dried. The Klebsiella pneumoniae cultures were autoclaved at $15 \mathrm{lb}$./sq.in. for $10 \mathrm{~min}$. before centrifugation.

Determination of the phosphorus-containing compounds. The determination of phosphorus-containing compounds was initially carried out by Mitchell \& Moyle's (1951 $a, b, 1954$ ) method (summarized in Fig. 1), which was an adaptation of the Schmidt \& Thannhauser (1945) procedure, thus giving an estimate of the following fractions: acid-soluble inorganic phosphorus (AI); acidsoluble organic phosphorus (AO); lipid phosphorus (L); pentosenucleic acid phosphorus (PNAP); deoxypentose nucleic acid phosphorus (DNAP); phosphoprotein phosphorus; XSP phosphorus. Phosphorus was determined as described by Jones, Lee \& Peacocke (1951). After extraction of the lipids the organisms were dried in vacuo over silica gel instead of over phosphorus pentoxide in order to eliminate any possibility of contamination with the latter. The XSP phosphorus was obtained by subtracting from the total phosphorus of the 'PNA fraction' the phosphoprotein phosphorus (estimated as the inorganic phosphorus of the PNA fraction) and the PNA phosphorus, the latter being calculated from the optical extinction of the solution at $260 \mathrm{~m} \mu$. For this purpose Mitchell \& Moyle assumed that the absorption of other components at $260 \mathrm{~m} \mu$. was negligible and that the $\epsilon_{p}$ value of all the pentose nucleic acids was 10,000 under the conditions of the estimation. $\left(\epsilon_{p}=30 \cdot 98 E /\right.$ cl, where $\boldsymbol{E}=$ extinction of the solution; $c=$ concentration of phosphorus in g./l.; $l=$ thickness of absorbing layer in cm.; Chargaff \& Zamenhof, 1948.)

It became obvious, however, that this method of estimating PNA was inaccurate, both due to the fact that absorption at $260 \mathrm{~m} \mu$. of components other than nucleotides was far from negligible and that the $\epsilon_{p}$ values of PNA vary according to the source and are not equal to 10,000. The PNA was, therefore, subsequently determined by separation of the nucleotides of the PNA fraction by paper electrophoresis on Whatman No. 3 paper at pH 3.5 for $8.5 \mathrm{hr}$. at 1400 volts by Crosbie, Smellie \& Davidson's (1953) method as previously described (Foster, Jones \& Rizvi, 1956). The nucleotides were eluted from the paper with phosphate buffer ( $\mathrm{pH} \mathrm{7}$ ) and estimated spectrophotometrically. With pure yeast PNA $95 \%$ recovery was obtained. When applied to the PNA fractions of the micro-organisms, good separation of the nucleotides was not obtained, however. Since this was thought to be due to the presence of salts, $\mathrm{N}-\mathrm{KOH}$ was used to digest the organisms instead of $\mathrm{N}-\mathrm{NaOH}$, and perchloric acid to precipitate DNA at $\mathrm{pH} 1$ instead of trichloroacetic and hydrochloric acids. After separating the DNA, protein, and potassium perchlorate precipitates by centrifugation, the supernatant liquid was adjusted to $\mathrm{pH} 4$ and freeze-dried. The nucleotides were then extracted from the freeze-dried material with $60 \%(\mathrm{v} / \mathrm{v})$ ethanol in water and applied to the paper. With pure yeast PNA, 95\% recovery was obtained. This showed that there was a negligible loss of nucleotides on the potassium perchlorate precipitate (cf. Elson, Trent 
\& Chargaff, 1955). The non-interference of other cell constituents in the separation was established by estimating the nucleotide content of yeast PNA; in presence and in absence of a yeast extract. Satisfactory separation of the nucleotides was obtained and the recovery of PNA was again $95 \%$. Later work showed that the analysis could be improved in the following respects. (1) It was not necessary to adjust the $\mathrm{pH}$ value of the solution of nucleotides from $\mathrm{pH} 1$ to $\mathrm{pH} 4$ in order to achieve separation. (2) Whatman No. 1 paper could be used instead of Whatman No. 3, thereby decreasing the ultraviolet absorption of the blanks and simplifying the elution of the nucleotides. (3) Freeze drying of the PNA fraction and subsequent extraction of the nucleotides with $60 \%(\mathrm{v} / \mathrm{v})$ ethanol in water was not necessary if, after placing the ionophoretogram on the glass plates in the usual manner, it was left for $15 \mathrm{~min}$. before passing the current. This allowed all the material to dissolve in the buffer and so prevented undissolved fragments of the PNA fraction from interfering in the separation of the nucleotides. (4) More rapid and complete extraction of the nucleotides from the paper was obtained by the use of $0.1 \mathrm{~N}$ $\mathrm{HCl}$ at $37^{\circ}$ for $18 \mathrm{hr}$. instead of phosphate buffer of $\mathrm{pH} 7$. Degradation of the nucleotides was negligible and the recovery of PNA was in this case $97-100 \%$ of the theoretical. The XSP content was then determined using this more accurate value for the PNA phosphorus. The final procedure is shown in Fig. 1.

\section{RESULTS}

\section{Distribution of phosphorus-containing compounds in micro-organisms}

A number of Gram-positive and Gram-negative micro-organisms were analysed by the methods described above. The results (Table 1) show several marked differences from those obtained by Mitchell \& Moyle. Using the method of these authors for calculating the XSP content, the distinction between Grampositive and Gram-negative organisms was not nearly so marked as the earlier results (Mitchell \& Moyle, 1954) suggested. Thus, although, in general, the Gram-positive organisms appeared to contain more XSP factor than did the Gram-negative species, one or two anomalies were found; Klebsiella pneumoniae appeared to have a higher XSP content than did baker's yeast and Aerobacter aerogenes had an appreciable 'negative XSP content'.

From the results obtained by using the electrophoretic method for the estimation of PNA, it was obvious that all the organisms had an appreciable XSP content and that the low values obtained for Gram-negative organisms by Mitchell \& Moyle's method were due mainly to the presence of nonnucleotide, ultraviolet-absorbing material in the PNA fraction and, to a less extent, to the use of an inaccurate $\epsilon_{p}$ value for the estimation of PNA. The $\epsilon_{p}^{260}$ values for the PNA from various micro-organisms are shown in Table 2.

\section{Non-nucleotide ultraviolet-absorbing components}

The ultraviolet (u.v.) absorption spectra of the PNA fractions from all the organisms studied were not typical of pure ribonucleotides, the absorption at $220 \mathrm{~m} \mu$. being much higher than that at $260 \mathrm{~m} \mu$. (Figs. 2 and 3 show curves 
Freeze-dried organisms (40 mg.)

Lipid extracted as described by Mitchell

\& Moyle (1951 b)

\author{
Residue. Extracted with cold $5 \%$ Ether extract \\ $(\mathbf{w} / \mathrm{v})$ trichloroacetic acid, washed $\quad$ Lipid phosphorus (L) determined
} twice with water

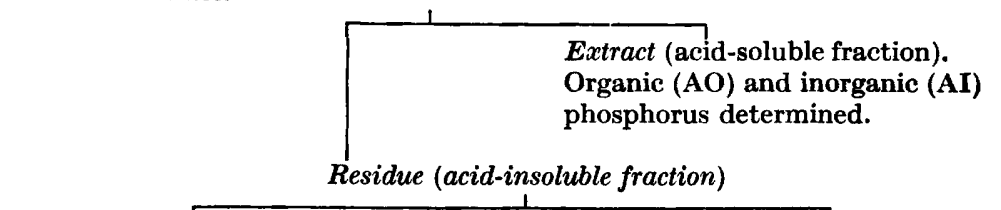

Mitchell \& Moyle's procedures Modified procedure

After drying, dispersed in $\mathrm{N}-\mathrm{NaOH}(4 \mathrm{ml}$.), incubated at $37^{\circ}$ for $15 \mathrm{hr}$. and then $10 \mathrm{~N}-$ $\mathrm{HCl}(0.4 \mathrm{ml}$.) and $30 \%$ trichloroacetic acid $(0 \cdot 88 \mathrm{ml}$.) added. Precipitate centrifuged off.

\begin{tabular}{|c|c|}
\hline $\begin{array}{l}\text { Precipitate } \\
\text { DNA }\end{array}$ & $\begin{array}{l}\text { Supernatant } \\
\text { 'PNA fraction' }\end{array}$ \\
\hline
\end{tabular}

Total phosphorus $\left(p_{1}\right)$ and inorganic phosphorus $\left(p_{2}\right)$ determined. $*$ The optical density at $260 \mathrm{~m} \mu$. was measured and the PNA phosphorus $\left(p_{3}\right)$ calculated using an $\epsilon_{p}$ value of 10,000 $\mathrm{XSP}=p_{1}-\left(p_{2}+p_{3}\right)$
After drying, dispersed in N-KOH (4 ml.), incubated at $37^{\circ}$ for $15 \mathrm{hr}$. and then $60 \%$ perchloric acid $(0.4 \mathrm{ml}$.) added and the precipitate centrifuged off.

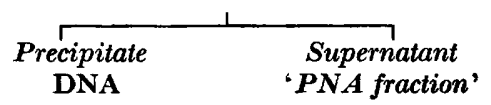

Total phosphorus $\left(p_{4}\right)$ and inorganic phosphorus $\left(p_{5}\right)$ determined. Optical density at $260 \mathrm{~m} \mu$. measured and the 'apparent PNA phosphorus' $\left(p_{6}\right)$ calculated using $\epsilon_{p}$ value of 10,000. The fraction was subjected to paper electrophoresis and the nucleotide phosphorus $\left(p_{7}\right)$ estimated and the non-nucleotide ultraviolet-absorbing material detected.

$\mathrm{XSP}=p_{4}-\left(p_{5}+p_{7}\right)$

'Apparent XSP' $=p_{4}-\left(p_{6}+p_{6}\right)$

* In the present investigation a difficulty was encountered in determining the optical absorption of the PNA fraction due to the use of trichloroacetic acid as a precipitant for the DNA. Trichloroacetic acid has an appreciable absorption at $260 \mathrm{~m} \mu$. for which it was difficult to correct due to the absorption of an unknown quantity of trichloroacetic acid on the DNA and protein precipitate. In order to eliminate this uncertainty the PNA fraction was extracted four times with ether before the optical density was determined. A blank was obtained by similarly extracting a solution of trichloroacetic acid and hydrochloric acid of the same strength was used to precipitate the DNA. There is no indication of how the blank was determined by Mitchell \& Moyle.

Fig. 1. Procedures used for the determination of the phosphorus-containing compounds in micro-organisms.

for two of the organisms; the others were similar.) This indicated the presence of other u.v.-absorbing components in this fraction. These could be separated from the nucleotides by paper electrophoresis at $\mathrm{pH} \mathrm{3.5,} \mathrm{when} \mathrm{the} \mathrm{nucleotides}$ migrated to the anode and the other components either remained on the starting line or migrated to the cathode (Pl. 1, fig. 1). These components were eluted, combined, and their u.v.-absorption spectra determined. The spectra (Figs. 2, 3) were similar for the components from all the organisms and showed 
no definite peak. This absorption contributed on the average about $30 \%$ to the total absorption of the PNA fraction at $260 \mathrm{~m} \mu$. (Table 1).

Table 2. $\epsilon_{p}^{260}$ values at $\mathrm{pH} 1$ of $P N A$ from various micro-organisms

\begin{tabular}{lllc}
\multicolumn{1}{c}{ Organism } & $\epsilon_{p}^{260}$ & \multicolumn{1}{c}{ Organism } & $\epsilon_{p}^{260}$ \\
Bacillus subtilis & 10,600 & Aerobacter aerogenes & 10,800 \\
Clostridium roelchii & 10,900 & A. cloacae & 10,900 \\
Sarcina lutea & 10,600 & Escherichia coli & 10,500 \\
Streptococcus faecalis & 10,450 & Klebsiella pneumoniae & 10,900 \\
Baker's yeast & 10,600 & &
\end{tabular}

An alternative method for the isolation of these components was to freeze dry the PNA fraction and extract the nucleotides with $60 \%(\mathrm{v} / \mathrm{v})$ ethanol in water. Most of the non-nucleotide u.v.-absorbing material remained insoluble. This insoluble material gave a positive ninhydrin reaction and a negative reaction for carbohydrate, and therefore appeared to be mainly peptide in nature. This was confirmed by hydrolysing the PNA fraction of Klebsiella pneumoniae with $5 \mathrm{~N}-\mathrm{HCl}$ and separating the products by paper electrophoresis at $\mathrm{pH} \mathrm{5 \cdot 0.}$. Upon spraying the paper with ninhydrin, spots corresponding to basic, neutral and acidic amino acids were obtained.

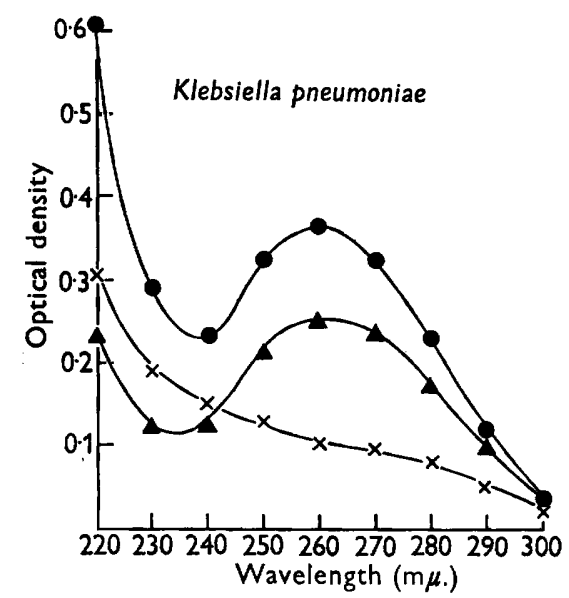

Fig. 2

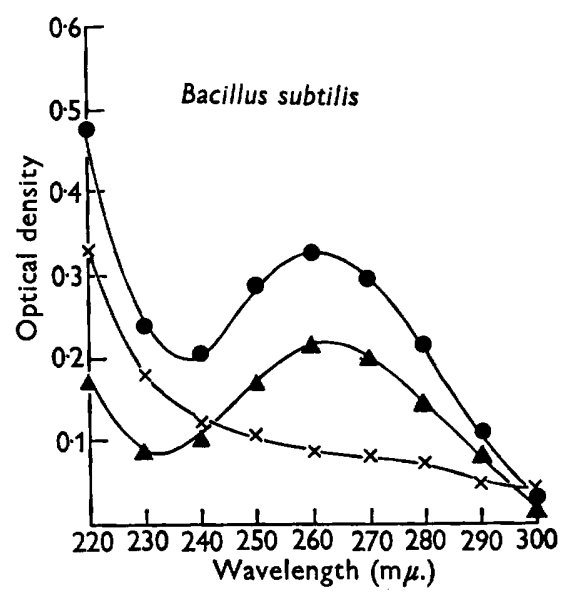

Fig. 3

Figs. 2, 3. Ultraviolet absorbing components of the PNA fractions of Klebsiella pneumoniae (Fig. 2) and of Bacillus subtilis (Fig. 3). nucleotide components; $\boldsymbol{\Delta}-\boldsymbol{\Lambda}$, nucleotides.

The 'XSP factor' of Klebsiella pneumoniae

Further evidence for the presence of non-nucleotide phosphorus-containing compounds (XSP) in Klebsiella pneumoniae was obtained by the use of radioactive phosphorus $\left({ }^{32} \mathrm{P}\right)$. The organisms were grown for $18 \mathrm{hr}$. at $37^{\circ}$ in $500 \mathrm{ml}$. medium containing 3 millicuries (mc.) of ${ }^{32} \mathrm{P}$ as inorganic phosphate. The culture was then autoclaved, and the organisms centrifuged off, washed with $\mathbf{0 . 8 5} \%(\mathrm{w} / \mathrm{v})$ sodium chloride and freeze dried. The PNA fraction was then prepared as usual and subjected to paper electrophoresis on Whatman No. 3MM 
paper at $\mathrm{pH} 3.5$ for $17.75 \mathrm{hr}$ at $900 \mathrm{~V}$. The u.v.-absorbing compounds were detected in the usual way and the compounds containing ${ }^{32} \mathrm{P}$ detected by autoradiography. The results (Pl. 1, fig. 2) show that in addition to the four nucleotides there were present at least ten other phosphorus-containing compounds, some of which coincided with some of the non-nucleotide u.v.-absorbing components. Since this electrophoretogram was run for a considerably longer time than that shown in Pl. 1, fig. 1, some of the non-nucleotide u.v.absorbing components had run off the end of the paper.

Some of the components of the XSP factor of Klebsiella pneumoniae were isolated and partly identified as follows (cf. Mitchell \& Moyle, 1951 $a$ ). The PNA fraction was prepared as previously described (without the use of ${ }^{32} \mathrm{P}$ ) from $40 \mathrm{mg}$. freeze-dried organisms. This fraction was adjusted to $\mathrm{pH} 9$ with ammonia, $95 \%(\mathrm{v} / \mathrm{v})$ ethanol in water added $(1 \mathrm{vol}$.$) and the mixture allowed$ to stand at room temperature for 2 days. The precipitate (non-nucleotide u.v.-absorbing material) was centrifuged off and to the supernatant liquid there was added $\mathrm{M}-\mathrm{BaCl}_{2}$ solution $(0.5 \mathrm{ml}$.). The precipitate thus formed was centrifuged off, washed twice with $60 \%(\mathrm{v} / \mathrm{v})$ ethanol in water, extracted with $0 \cdot 1 \mathrm{~N}-\mathrm{H}_{2} \mathrm{SO}_{4}$ and the precipitate of barium sulphate centrifuged off. The supernatant liquid was adjusted to $\mathrm{pH} 5$ with barium hydroxide solution and the barium sulphate precipitate centrifuged off.

In order to remove nucleotides from the supernatant liquid a charcoal slurry ( 5 mg. charcoal washed by the method of Lipkin, Talbert \& Cohn, 1954, in $1 \mathrm{ml}$. distilled water) was added dropwise until all the nucleotides had been adsorbed. This was shown by the absence of a peak at $260 \mathrm{~m} \mu$. in the optical absorption curve of the solution after the removal of the charcoal. The resulting solution contained non-nucleotide u.v.-absorbing material, a small quantity of inorganic phosphate and $64 \%$ of the XSP factor originally present in the PNA fraction. By a similar procedure, $63 \%$ of the XSP factor of Aerobacter cloacae was obtained. The solution obtained from Klebsiella pneumoniae was freeze-dried and the components separated by paper chromatography by techniques described by Benson et al. (1951) and Hanes \& Isherwood (1949).

Acid-washed Whatman No. 1 and No. 4 papers were used. The phosphates were detected by the use of the spray reagent described by Hanes \& Isherwood (1949). After spraying, the papers were dried, heated at $80^{\circ}$ for $10 \mathrm{~min}$. and then exposed to u.v. radiation for $10 \mathrm{~min}$. as recommended by Bandurski \& Axelord (1951). After irradiation most of the organic phosphates appeared immediately as blue spots but some only appeared after some time (in one case 12-15 hr.).

When chromatograms were developed on Whatman No. 1 paper with $n$-propanol + water + ammonia (sp.gr. 0.880); $(60: 10: 30)$, for $18 \mathrm{hr}$., five spots of $R_{F}$ values $0,0.11,0.26,0.38$, and 0.67 were detected. When a mixture of isopropanol +water + ammonia (sp.gr. 0.880), (70:6:30), was used as the solvent on Whatman No. 1 paper after $25 \mathrm{hr}$. development, seven spots of $\boldsymbol{R}_{F}$ values $0,0.065,0 \cdot 17,0.26,0.39,0.54$, and 0.69 were obtained, and on Whatman No. 4 paper after $9 \mathrm{hr}$. development, seven spots of $R_{F}$ values, $0,0 \cdot 10,0 \cdot 33$, $0 \cdot 46,0 \cdot 62,0.72$, and 0.86 were detected. It appeared, therefore, that at least 
seven phosphorus-containing compounds were present. Table 3 shows that two of these corresponded in $\boldsymbol{R}_{F}$ values with $\alpha$-glycerophosphate and inositol phosphate, respectively. The colour of the spot for inositol phosphate was lighter than that of the corresponding spot of the XSP factor. This may have been because in the latter case peptide material was present at the same position on the chromatograms.

Table 3. $R_{F}$ values of $\alpha$-glycerophosphate, inositol phosphate and phosphate fractions of Klebsiella pneumoniae

\begin{tabular}{|c|c|c|c|c|c|}
\hline \multirow[b]{2}{*}{ Solvent } & \multirow[b]{2}{*}{$\begin{array}{l}\text { Whatman } \\
\text { Paper } \\
\text { No. }\end{array}$} & \multicolumn{4}{|c|}{ Component or compound } \\
\hline & & $\begin{array}{c}\alpha \text {-Glycero- } \\
\text { phosphate }\end{array}$ & $\begin{array}{c}\text { Component } \\
\text { of 'XSP' } \\
\text { factor } \\
R_{F} \text { values }\end{array}$ & $\begin{array}{c}\text { Inositol } \\
\text { phosphate }\end{array}$ & $\begin{array}{c}\text { Componen } \\
\text { of 'XSP' } \\
\text { factor }\end{array}$ \\
\hline $\begin{array}{l}n \text {-Propanol + water }+ \\
\text { ammonia (sp.gr. } 0 \cdot 880) \\
(60: 10: 30)\end{array}$ & $\mathbf{1}$ & 0.25 & $0 \cdot 25$ & $0 \cdot 11$ & $0 \cdot 11$ \\
\hline $\begin{array}{l}\text { isoPropanol + water + } \\
\text { ammonia (sp.gr. 0.880); } \\
(70: 6: 30)\end{array}$ & $\begin{array}{l}1 \\
4\end{array}$ & $\begin{array}{l}0.54 \\
0.72\end{array}$ & $\begin{array}{l}0.54 \\
0.72\end{array}$ & $\begin{array}{l}0 \cdot 39 \\
0 \cdot 63\end{array}$ & $\begin{array}{l}0 \cdot 39 \\
0 \cdot 62\end{array}$ \\
\hline
\end{tabular}

\section{DISCUSSION}

The results of this investigation show that pentose nucleic acid (PNA) cannot be estimated accurately in micro-organisms by the determination of either the optical absorption at $260 \mathrm{~m} \mu$. or the phosphorus content of the 'PNA fraction' of the Schmidt \& Thannhauser (1945) procedure. This is due to the presence in this fraction of phosphorus-containing impurities and u.v.-absorbing impurities. An accurate estimation of PNA was obtained, however, by removing these impurities by paper electrophoresis and estimating the nucleotides spectrophotometrically. The use of this technique showed that both Grampositive and Gram-negative organisms contained in their PNA fractions nonnucleotide, phosphorus-containing compounds (XSP factor). The results of Mitchell \& Moyle $(1950,1954)$, from which it was concluded that only Grampositive organisms contained this factor, were apparently due in part to their having ignored the presence of non-nucleotide u.v.-absorbing compounds.

The results obtained in this investigation for the XSP contents of the various micro-organisms were, where comparison was possible, much lower than those of Mitchell \& Moyle when these authors' own method was used. It seems possible that this may have been due to the fact that in this work the organisms were grown in a Lemco + peptone medium at $37^{\circ}$, and that Mitchell $\&$ Moyle used a casein digest medium at $25^{\circ}$. In Klebsiella pneumoniae, an organism not analysed by Mitchell \& Moyle, however, the XSP content was higher than any recorded by Mitchell \& Moyle for a Gram-negative organism and higher than that found in this work in baker's yeast. When the present more accurate method of estimating PNA was used, however, the results for Gram-positive organisms were in fair agreement with those of Mitchell \& Moyle but those for Gram-negative organisms were much higher. 


\section{Role of phosphorus compounds in Gram reaction}

The presence of 'XSP factor' in a Gram-negative organism has been confirmed both by the experiment with ${ }^{32} \mathrm{P}$ and by the isolation of non-nucleotide phosphorus-containing compounds from Klebsiella pneumoniae. Two of these have been tentatively identified as $\alpha$-glycerophosphate and inositol phosphate, respectively.

The presence of non-nucleotide phosphorus-containing compounds in the PNA fraction of higher organisms has been reported by a number of workers. Davidson \& Smellie (1952) found that this fraction from liver cells contained, in addition to the four nucleotides, at least six other phosphorus-containing compounds; and Logan, Mannell \& Rossiter (1952) found that in nerve tissue, the non-nucleotide phosphorus-containing compounds accounted for more than $50 \%$ of the total phosphorus of the PNA fraction. It appears, therefore, that non-nucleotide phosphorus-containing compounds occur in the PNA fraction of many organisms and are not peculiar to Gram-positive microorganisms. There is therefore no evidence to connect the Gram-positive reaction of the micro-organisms examined here with the presence of an 'XSP factor', nor is there need to abandon the previous contention that the Gram staining properties are associated with a complex involving magnesium ribonucleate.

The authors thank Mr E. T. J. Chelton, F.I.M.L.T., for technical assistance and the Medical Research Council for a grant for expenses. One of us (S.B.H.R.) was in the receipt of a Scholarship under the Colombo Plan from the Commonwealth Relations Office, London, for which many thanks are expressed.

\section{REFERENCES}

BANDURSki, R. S. \& AXELORD, B. (1951). The chromatographic identification of some biologically important phosphate esters. J. biol. Chem. 193, 405.

Bartholomew, J. W. \& Umbreit, W. W. (1944). Ribonucleic acid and the Gram stain. J. Bact. 48, 567.

Benson, A. A., Bassham, J. A., Calvin, M., Goodale, T. C., HaAs, V. A. \& Stepka, W. (1951). The path of carbon in photosynthesis. V. Paper chromatography and radio-autography of the products. J. Amer. chem. Soc. 72, 1710.

Chargaff, E. \& Zamenhof, S. (1948). The isolation of highly polymerised desoxypentosenucleic acid from yeast cells. J. biol. Chem. 173, 327 .

Crosbie, G. W., Smeldie, R. M. S. \& Davidson, J. N. (1953). Phosphorus compounds in the cell. 5. Composition of the cytoplasmic and nuclear ribonucleic acids of the liver cell. Biochem. J. 54, 287.

Davidson, J. N. \& Smellie, R. M. S. (1952). Phosphorus compounds in the cell. 3 . The incorporation of radioactive phosphorus into the ribonucleotide fraction of liver tissue. Biochem. J. 52, 599.

Elson, D., Trent, L. W. \& Chargaff, E. (1955). The nucleotide composition of pentosenucleic acids in different cellular fractions. Biochim. biophys. Acta, $17,362$.

Foster, A. B., Jones, A. S. \& Rizvi, S. B. H. (1956). Ionophoresis of nucleic acid components. Chem. \& Ind. p. 914.

HANES, C. S. \& Isherwood, F. A. (1949). Separation of the phosphoric esters on the filter paper chromatogram. Nature, Lond. 164, 1107.

Henry, H. \& Stacey, M. (1943). Histochemistry of the Gram staining reaction of micro-organisms. Nature, Lond. 151, 671. 
Henry, H. \& Stacey, M. (1946). Histochemistry of the Gram staining reaction of micro-organisms. Proc. Roy. Soc. B, 133, 391.

Henry, H., Stacey, M. \& Teece, E. G. (1945). Nature of the Gram complex in micro-organisms. Nature, Lond. 156, 720.

Jones, A. S., Lee, W. A. \& Peacocke, A. R. (1951). The determination of phosphorus in deoxypentosenucleic acids. J. chem. Soc. p. 623.

Jones, A. S., Muggleston, P. W. \& Stacey, M. (1950). The Gram complex in Clostridium welchii. Nature, Lond. 166, 650.

Lipkin, D., TAlbert, P. T. \& Cohn, M. (1954). The mechanism of the alkaline hydrolysis of ribonucleic acid. J. Amer. chem. Soc. 76, 2871.

Logan, J. E., Manneld, W. A. \& Rossiter, R. J. (1952). Estimation of nucleic acids in tissue from the nervous system. Biochem. J. 51, 470.

Mrtcheld, P. \& Moyle, J. (1950). Occurrence of a phosphoric ester in certain bacteria: its relation to Gram staining and penicillin sensitivity. Nature, Lond. 166, 218.

Mrtcheld, P. \& Moyse, J. (1951 a). Isolation of hydrolytic products of a glycerophospho-compound from Micrococcus pyogenes. J. gen. Microbiol. 5, 966.

Mitcheld, P. \& Moyle, J. (1951 $b$ ). The glycero-phosphoprotein complex envelope of Micrococcus pyogenes. J. gen. Microbiol. 5, 981.

Mitchell, P. \& MoYle, J. (1954). The Gram reaction and cell composition: nucleic acids and other phosphate fractions. J. gen. Microbiol. 10, 533.

Schmidt, G. \& Thannhauser, S. J. (1945). A method for the determination of deoxyribonucleic acid, ribonucleic acid and phosphoproteins in animal tissues. J. biol. Chem. 161, 83.

\section{EXPLANATION OF PLATE}

Fig. 1. Electrophoretogram of u.v.-absorbing components of PNA fraction of Klebsiella pneumoniae. $\times \mathbf{0 . 4}$.

Fig. 2. Electrophoretogram of the PNA fraction of Klebsiella pneumoniae. $(\times 0 \cdot 3) . \mathrm{X}=$ autoradiograph showing components containing ${ }^{32} \mathrm{P} ; \mathrm{Y}=$ photograph showing u.v.-absorbing components; $\mathbf{A}=$ adenylic acid; $\mathrm{C}=$ cytidylic acid; $\mathbf{G}=$ guanylic acid; $\mathrm{U}=$ uridylic acid; $\mathbf{P}_{1}-\mathbf{P}_{10}=$ unidentified phosphorus-containing compounds; origin line between $\mathbf{P}_{\mathbf{1}}$ and $\mathbf{P}_{\mathbf{2}}$. 
Journal of General Microbiology, Vol. 18, No. 3

Electrophoretogram of ultraviolet absorbing components of

K. pneumonize

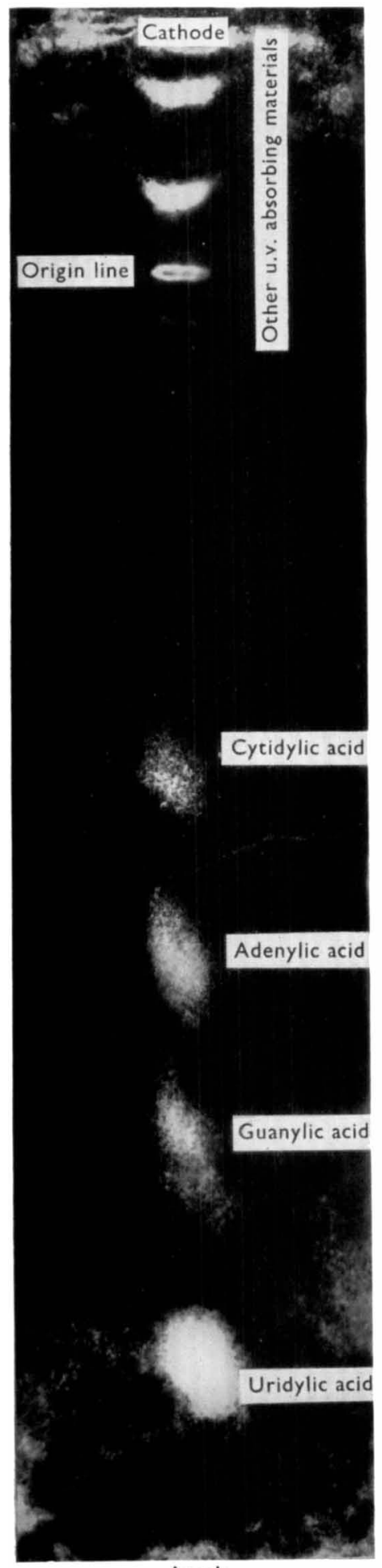

Anode

Fig. 1

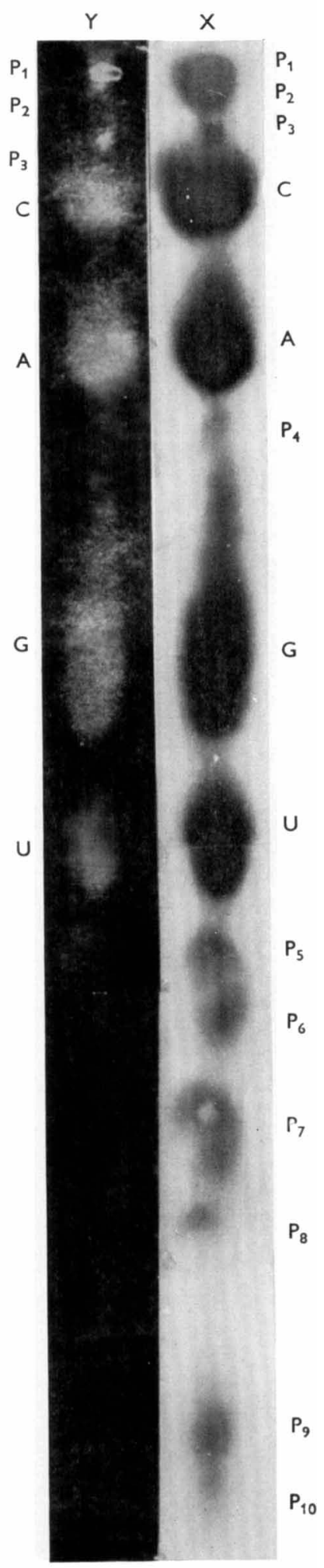

Fig. 2

A. S. Jones, S. B. H. Rizvi and M. Stacey-Role of phosphorus compounds in Gram reaction. Plate 1 